\title{
SUPPLY CHAIN-BASED CONFLICT: A STUDY FROM TEXTILE EXPORTERS' PERSPECTIVES
}

\author{
*Süleyman BARUTÇU \\ **Hulusi DOĞAN \\ *Esin BARUTÇU \\ ***Atik KULAKLI \\ *Pamukkale University, Turkey \\ **Akdeniz University, Turkey \\ ***Beykent University, Turkey
}

\begin{abstract}
Conflict is a common event in interactions among people, companies and supply chains. The main objectives of this paper are to (1) explain the importance of conflict management in a supply chain, (2) bring out the sources and resolution methods of the supply chain-based conflicts, and (3) explore the differences between upstream and downstream textile supply chain-based conflicts. The survey conducting on textile companies provides insight into supply chain-based conflict from textile exporter perspectives. According to the survey results, the conflicts between the supply chain partners just appear to be a fact of business atmosphere. The underlying sources of conflicts are price changes for downstream partners and demand for faster delivery from upstream partners. The underlying conflict resolution methods are compromising for downstream partners and sharing for upstream partners. Moreover, the independent-samples T-tests make clear that the sources and resolutions methods of supply chain-based conflicts are different between downstream and upstream supply chain, and cannot be generalized for all the supply chains. Thus, the supply chain-based conflict management should be divergent for downstream and upstream partners.
\end{abstract}

Keywords: Supply Chain Management, Conflict, Conflict Management, Textile Supply Chain

\section{INTRODUCTION}

Over the last decade, the competitive business atmosphere has pushed companies to compete not solely on their own capabilities but with their entire supply chain and suppliers (Hult et al., 2007). Moreover, increased customer requirements and globalization have forced managers to ensure that their organization's resources are well aligned not only across all functional areas but also throughout the entire supply chain (Vachon et al., 2009). At the present time, an effectively managed supply chain is one of the main requirements because the efficiency of companies is heavily dependent on their suppliers and supply chain partners. Thus, the supply chain, its processes and supply chain management have been begun to be implemented increasingly by companies as an important strategic option for pursuing their strategies from automobile to textile industries.

Supply chain management is a field, comprised of many disciplines, especially Business (such as Marketing, Management and Finance), Production Management, Logistics and Industrial Engineering etc. Therefore, it has been studied in respect of a number of perspectives. One of them is the conflict management in a supply chain, because conflict is inevitable between people, companies and supply chains, and it is important for the success of companies and their relationships with the suppliers. In the management literature, most of the conflict researchers studied the types of conflict between workers, people or groups in a company, between company and persons. In the marketing literature, most researches on conflict focus on channel relationships and conflicts between marketing and production departments or people. In the supply chain management literature, there are limited researches on conflict management focused on the sources of conflict, the factors leading to conflict and the methods for conflict resolutions in order to reduce the negative effects and increase the positive effects of conflict. 
This paper analyses the sights of conflict management in the textile supply chain so as to accomplish harmonious and productive working relationships within both downstream and upstream textile supply chain. Thus, the concepts of supply chain, supply chain management, conflict, conflict management, the textile supply chain, the causes and resolutions of conflicts in the textile supply chain are explained. The survey results conducted on textile exporters to understand which conflict and conflict management methods are used in supply chain-based conflict are presented, and what are the differences between downstream and upstream textile supply chain-based conflict are compared.

\section{CONCEPTUAL FRAMEWORK}

\section{Supply Chain Management}

As the world economy becomes increasingly competitive, competition among companies is becoming fierce and no longer between companies and companies, but supply chains to supply chains, and companies can no longer effectively compete in isolation of their suppliers and other entities in the supply chain (Lummus and Vokurka, 1999; Christopher, 2000). Hence, one of the most significant paradigm shifts of modern business management is that individual companies no longer compete as solely autonomous entities, but rather as supply chains (Lambert and Cooper, 2000). Moreover, sustaining competitiveness and the resulting profitability depends less on the ability to raise prices. Instead, companies need to compete on the basis of product innovation, higher quality, and faster response times, all of which must be delivered, in most cases simultaneously and always at the lowest costs attainable. Those competitive dimensions can not be delivered without an effectively managed a supply chain (Presutti, 2003). As a consequence, competition shifts from company versus company to supply chain versus supply chain, and the supply chain management has been considered as the most popular operations strategy for improving organizational competitiveness, because this system incorporates the entire exchange of information and movement of products between suppliers and final customers, including manufacturers, distributors, retailers, and any other companies within the extended supply chain (Gunasekaran et al., 2008).

A supply chain can be defined as a network of various organizations involves both through upstream and downstream linkages in different kinds of activities and processes (Christopher, 1998) and involves interdependent units within a company and across divisions that belong to both downstream and upstream partners (Ballou et al., 2000). The term supply chain management has been used to describe the planning and control of materials and information flows as well as logistics activities not only internally within a company but also externally between companies (Cooper et al., 1997). According to various studies, supply chain management can be defined in many ways. For example, the Global Supply Chain Forum defines Supply Chain Management as the integration and incorporation of key business processes from end user through original supplier that provides materials, products, services, and information that add value for customers and other stakeholders (Lambert et al., 1998; Soroor and Tarokh, 2006). Udin et al. (2006) defines supply chain management as a system that contains multiple entities, processes and activities from suppliers to customers. Stadtler (2004) summed up the many definitions of supply chain management by various authors and researchers as 'the task of integrating organizational units along a supply chain and coordinating materials, information and financial flows in order to fulfill customer demands with the aim of improving competitiveness of the supply chain as a whole.

Supply chain management aims at four major targets: (1) waste reduction; (2) time compression; (3) flexible response; and (4) unit cost reduction. These goals have been articulated in several contexts associated with supply chain management, emphasizing the importance of coordination. Companies practicing supply chain management seek to reduce waste throughout the supply chain by minimizing duplication, harmonizing operations and systems, and enhancing quality. When production and logistics processes are accomplished in less time, all entities in the supply chain are able to operate more efficiently, and primary outcome is the reduced inventories throughout the system (Brewer and Speh, 2000). Thus, supply chain management can positively impact many functions and outcomes of the company including product quality, customer responsiveness and resultant satisfaction, manufacturing cost control, product and market flexibility, and macro performance outcomes including market share and profitability (Meier et al., 2004).

Successful supply chain management requires cross-functional integration (Lambert and Cooper, 2000). The basic concept behind supply chain management is how the raw materials and information 
flow from the supplier to the manufacturer, before final distributions to customers as finished products or services. The capability of sharing and exchanging information is essential to improve the effectiveness of the supply chain management (Udin et al., 2006). Thus, the crucial task of supply chain management is to gather the customers' demand more efficiently by providing the right product, in the right quantity, at the right location, at the right time, and in the right situation. However, one of the problems that suppliers come across is conflict among companies in a specific supply chain. Although conflict can occur at anytime and anywhere in the human life, there are some differences between human life-based conflict and the supply chain-based conflict. Thus, it is important for the supply chain to manage conflict effectively so that the positive consequences of conflict can be realized. Coordinating and managing distributed entities in a supply chain is a challenging task due, in part, to conflicts present in such systems. If not handled effectively, the conflict can degrade the performance of the system (Blackhursta et al., 2008).

\section{Conflict and Conflict Management}

Conflict has been a hot topic studied by researchers in the discipline of psychology, sociology and business (Rahim, 2001), and is revised by academicians in the discipline of management, marketing, psychology and sociology etc. Whenever people or companies work together, conflict in a team, company or among companies are inevitable (Daft, 1997: 608), and a ubiquitous phenomenon that covers all activities among companies. Researchers, in different fields, have recognized conflict as an important issue that affects organizational and supply chain performance (Bradford et al. 2004: Lam and Chin, 2005). For example, there is a negative relationship between conflict intensity and performance of supply chain in terms of product quality, delivery time, meeting of target development costs and etc. The effects of conflict in the workplace are widespread and costly. Its prevalence, as indicated by three serious studies, shows that $24-60 \%$ of management time and energy is spent dealing with conflict. This leads to decreased productivity, increased stress among employees, hampered performance, high turnover rate (Fiore, 2004).

In the literature, conflict can be termed in many ways. For example, conflict can be defined as the interaction of interdependent people who perceive opposition of goals, aims, and values, and who see the other party as potentially interfering with the realization of these goals (Putnam and Poole, 1987), as disagreement between two or more individuals, groups or parties (Griffin, 1990: 531), any situation in which two or more parties feel themselves in opposition (Newstrom and Davis, 1997: 312), as a process that begins when company or people perceive that another company or person has negatively affected, or is about to negatively affects, something that the first party cares about (Robbins, 1998: 434) and as the behaviors or feelings of interdependent parties in response to potential or actual obstructions that impede one or more of the parties achieving their goals (Coughlan et al., 2001).

There are many studies about conflict in different areas. For example, Geyskens et al. (1998) studied conflicts in channel relationship and retailing. Shaw and Shaw (1998) analyzed conflicts between engineers and marketers from engineer's perspectives. Rahim (2001) asserted that conflict has both functional and dysfunctional outcomes. Functional outcomes include stimulating innovation and creativity, and better decision making, whereas dissatisfaction, mistrust, damaged commitment and relationship are the common dysfunctional outcomes. Bradford et al. (2004) researched supply chainbased conflict and how affect company performance. They analyzed (1) inter-personal conflict and (2) task conflict in the retailing industry because retailers increasingly were becoming involved with groups of other firms to improve their effectiveness in performing business activities. The results of their research show that conflict can have negative effects on network outcomes. Lam and Chin (2005) analyzed conflicts in new product development process. Kozan et al. (2006) analyzed conflict management in Turkish buyer-supplier relationships, and studied buyer-supplier relations from a conflict management perspective capturing data from 50 buyers in automakers and 72 suppliers. In sum, conflict has been studied in terms of conflict among departments, ideas, companies and individuals. Specifically, the area of supply chain-based conflict is particularly important due to importance of supply chain management.

\section{Conflict Management in the Textile Supply Chain}

Conflict Management in the textile supply chain is not a new concept, but it is a very important aspect of supply chain management dynamics and performance of textile companies. Since the conflict dif- 
fers from company to company and textile supply chain to food supply chain, on the one hand, the textile supply chain-based conflict can be defined as an ongoing state of disagreement and incompatibility between partners in the textile supply chain or the processes that start on when one supplier perceives that the other suppliers have bothered. On the other hand, the textile-based conflict management can be defined as the short or long-term management processes used to resolve disagreement and incompatibility. Pondy (1967) identified three conceptual models to deal with the major classes of conflict in organizations, (1) Bargaining Model: conflict among interest groups which are in competition for scarce resources; (2) Bureaucratic Model: conflict between a superior and a subordinate, or along any vertical dimension in the organizational hierarchy; (3) Systems Model: conflict among parties in a lateral or functional relationship, and in particular, the problems of coordination. The textile supply chain-based conflicts are related with all these models because there are many relationships among person and companies in the textile supply chain.

\section{The Sources of Supply Chain-Based Conflict}

Since conflict prevention is always easier than conflict handling, foreseeing sources of supply chainbased conflict will be more useful. In general, conflict is widespread within and among the supply chain partners, and there are some kinds of conflict arisen in the supply chain because of following reasons, (1) differences in objectives; (2) lack/scarcity of trust among the partners; (3) use of coercive power and strategies by chain members, (3) inefficient system structure, (4) win-lose mentality, (5) slippery and arduous global business environment, and (6) lack or scarcity of collaboration and cooperation within the organization and among the supply chain partners (Barutçu et al., 2005). Naturally, there is an ongoing conflict between manufacturing, finance and marketing departments because of different cultures, mentalities and goals of their managers and workers. For example, group or party interdependence, differences in goals, resource competition, and interpersonal dynamics etc. can cause conflict within and among organizations (Griffin, 1990: 532-533). Many times conflicts arise because individuals or groups are trying to control resources in pursuit of their own goals (Milgram et al., 1999: 297). Good supply chain management means openly talking through and coming to a real agreement on difficult organizational issues, such as authority, performance, collaborative decision-making, power imbalances, and the sharing of risks, costs, and improvement benefits. But, none of the system of collaboration is perfect. Moreover, the supply chain can often be complex because of the large network of suppliers and different objectives across the supply chain. The difficulties imposed by this complexity are compounded by the increase in competitive pressure with the demand for ever greater levels of responsiveness, shorter cycle times and a simultaneous increase in the complexity of products (Handfield and Nichols, 1999). Buyers and suppliers would also conflict intensively for blaming each other for responsibility once the consequences such as redesign and delay occur because of the different interpretations of product specifications (Lam and Chin, 2005). For example, at a manufacturing company, when the supplier of a component promises delivery dates to another supplier and components don't arrive on time, production facilities fail, customers may change or cancel orders, etc. and conflict arises among the parties involved. The level of structure in the relationship can influence the potential of conflict. Structure, by formalizing the form, process, and content of the relationship implies a level of agreement about mutual expectations. The structure of an organizational relationship is the level of specification of roles, obligations, rights, procedures, information flows, data, and analysis and computational methods used in the organizational relationship. Lack of structure would, therefore, contribute to the risk of conflict. Given the different levels of interdependence (pooled, sequential, and reciprocal), they imply different levels of structure and therefore imply different potentials for conflict (Kumar and Dissel, 1996). In a typical supply chain, there is a sequential interdependence among the partners and this kind of interdependence requires one group's output to serve as another group's input, thereby providing basis for great potential conflict (Gibson, 1997: 228).

\section{The Resolution of the Supply Chain-Based Conflict}

Generally, optimal level of conflict stimulates creativity, innovation, and improvements. But excessive level of conflict may harm relationships in the supply chain. Provided that textile companies are currently facing a conflict situation, they should look at the ultimate cause of this conflict. In the conflict resolution, conflict handling system that enables to handle with the conflict efficiently and effectively is important. The system is comprised of conflict management culture, conflict handling skill, conflict handling process, and conflict monitoring and improvement parts (Lam and Chin, 2005). Con- 
flict Resolution provides instruction on conflict resolution through an interactive relationship. A number of different models have been proposed with which to classify responses to conflict. Thomas (1976) conceptualized five conflict-handling styles as (1) competitive- one partner seeks to dominate the process, without regard for the others, (2) collaborative- partners seek to understand their differences and achieve a mutually beneficial solution., (3) avoidant- the conflict is recognized to exist but is suppressed by one or more parties, or handled by withdrawal., (4) accommodative- a partner becomes self-sacrificing to appease another, and places the interests of the other above their own., and (5) sharing models- each partner makes some concessions in order to reach a compromise for resolution conflict. According to Griffin (1990: 535-536), managers used one of the following conflict resolution strategies; avoidance, smoothing, compromise, and confrontation. The avoidance approach is simply to ignore the conflict and hope it will go away. Avoidance is sometimes effective in the short run, but it does little to resolve long run or acute conflict. Smoothing is minimizing the conflict and telling everyone that things will "get better." Compromise can work if it is used with care, but in most compromise situations someone wins and someone loses. The confrontation approach to conflict resolution involves bringing the parties together to confront the conflict. Newtrom and Davis (1997: 318319) repeated the same strategies with some minor differences; Avoiding, smoothing, forcing (using power tactics to achieve a win), compromising (searching for middle ground), confronting (facing the conflict directly and working it through to a mutually satisfactory resolution).

Textile-based conflict resolution means how to deal with conflict between supply chain partners. In order to manage conflict in the supply chain, Hau (1997) recommended that managers must create a more trusting relationship, enhances communication, and accurately measures gains and an investment in collaborative efforts. Johnston et al. (2004) emphasized that higher levels of interorganizational cooperative behaviors such as shared planning and flexibility in coordinating activities were found to be strongly linked to the supplier's trust and less conflict in supply chain. Bradford et al. (2004) emphasized that negative effects of conflict can be reduced by the use of the appropriate conflict management approaches. Collaboration, coordination, problem solving mechanisms systems and early supplier involvement in the design of products can provide better communications among supply chain partners, solve operational conflicts in supply chain, and facilitate better cooperation. Especially, effective communication enhances mutual understanding among companies in supply chain. Barutçu and Tanyeri (2004) offered the development of Strategic Supplier Alliances for better supplier-producer-distributor-buyer integration, less conflict and problems. Kumar and Dissel (1996) emphasized the importance of conflict management approach in the supply chain with the analogy of peace and diplomacy. Companies seeking to build and sustain successful supply chain need to recognize and implement the roles of corporate statesmen, diplomats, and peace observers who not only seek out build peace agreements and treaties (i.e., negotiate, design, and implement technical) but also guard against misunderstandings, misinterpretations, and perceived or real betrayals that may lead to the disintegration of the relationships. Blackhurst et al. (2008) presented a methodology, extending the concept of basic Petri Nets, to discover supply chain conflict before they occur and cause detrimental effects to system performance. The approach involves linking hierarchical levels of the supply chain system and detecting conflicts occurring when the single entities, each optimized for its own operations, are combined together in a supply chain. These conflicts are not obvious or intuitive in examining the single entities of the supply chain, but when integrated the conflicts are discovered by the methodology.

\section{TEXTILE INDUSTRY AND A GLOBAL TEXTILE SUPPLY CHAIN}

The textile companies in Denizli, Turkey are searching for new ways to improve their competitive positions. One of the ways of getting better competitive position for textile companies is to decrease their costs, because the lower production cost serves as a company's competitive tool in global markets. In this stage, the effective supply chain management can play a very important role for lower production cost, higher efficiency and less uncertainty in highly competitive textile industry.

The global textile supply chain is a world-wide network of suppliers, manufactures, warehouses, dis-tribution centers and retailers through which cotton are acquired, transformed and delivered to cus-tomers as textile products. The textile supply chains compete in lower cost, higher quality, perfect delivery and flexibility in diversity of textile products. There may be many processes, materials, sup- 
pliers and customers (final customers, retailers or hotels etc.) on information and for product (material/ machines/textile products) flow in the textile supply chain. Information flows along supply chains include sharing downstream information (for example sales, demand forecast, inventory information and logistics planning etc.) and upstream information (for example ordering, order status, production and logistics schedules etc.) in textile supply chain (Lee and Whang, 1999). As seen in Figure 1 , the textile industry has one of the longest and most complex supply chains characterized by the flow of bedclothes, pillowcase, towel, bathrobe, knitwear, apparel, dress, sheet, logistics services, money, and information both within and among business entities including suppliers, manufacturers, retailers and customers. It also includes all types of organizations engaged in transportation, warehousing, information processing, and materials handling, sourcing, procurement, production scheduling, manufacturing, order processing, inventory management and, finally, customer service are the functions performed throughout the supply chain. Another set of common terms in the supply chain language are upstream and downstream partners in the supply chain. These terms reflect the continuous nature of the physical supply process using a flow. Upstream partners refer to suppliers, but downstream partners refer to customers. In the case of textile industry, the upstream suppliers consist of manufacturing and processing textile products, the downstream suppliers hand concerns the distribution channel's functions where the product passes through to the final wholesaler/customer. Where external downstream and upstream functions are concerned, the textile managers of companies in Denizli, Turkey involved in each upstream and downstream suppliers and functions are responsible in making sure that the deliveries of textile products should be done as programmed to their destinations.

\section{Figure 1: The main stages in the global textile supply chain}

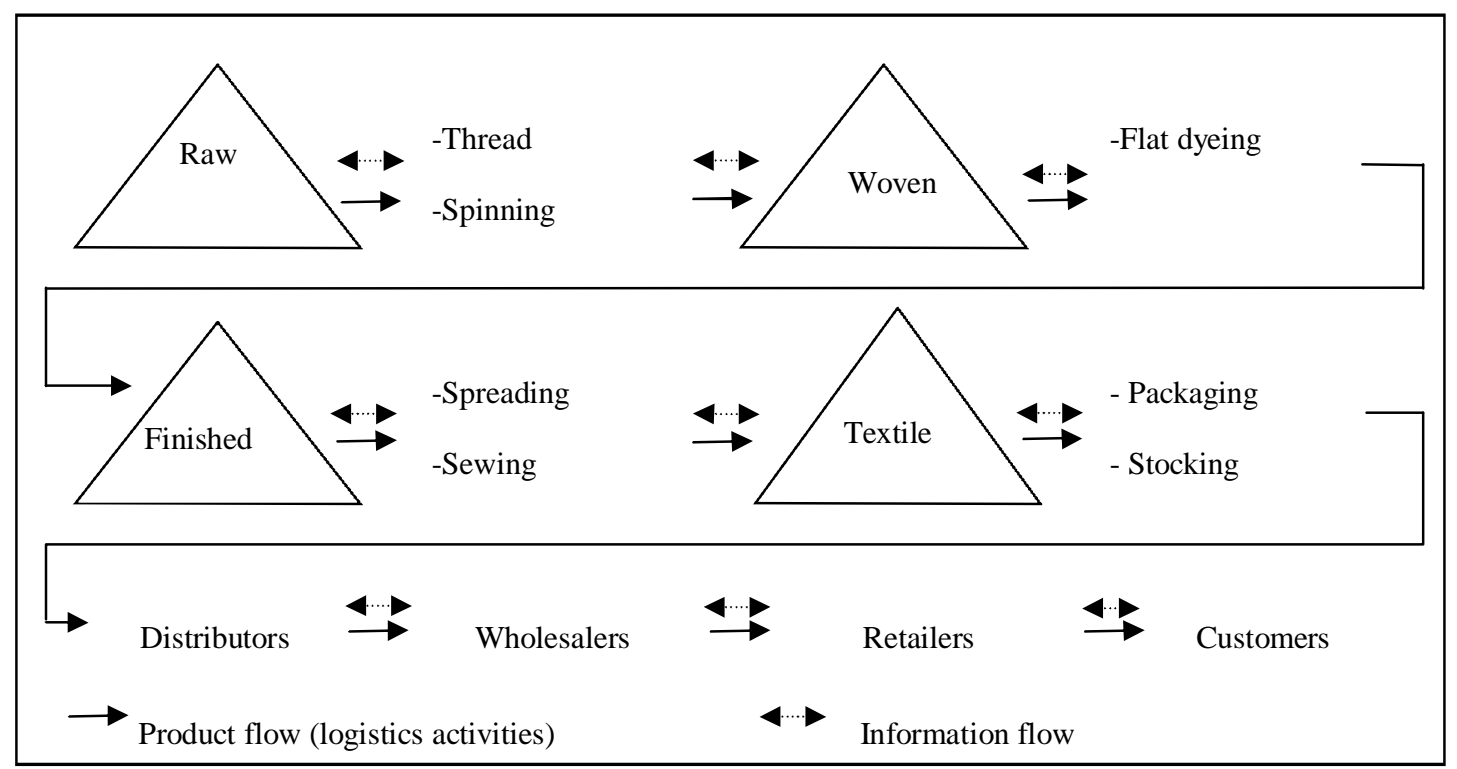

Textile exporters that are able to manage efficient relationships with their upstream and downstream suppliers have a greater guarantee of success in their activities, and get higher performance of the textile supply chain in delivering the correct textile products to the correct places and customers, at the correct time, in the correct condition and packaging in the correct quantity, with the correct documentation. Because of these multiplayer environments, it is expected that there will be differences in perspectives on how to work together in the textile supply chain. These differences in perspectives can create conflicts. Thus, managing a complex textile supply chain requires a coordination of all activities and high quality relationship without conflicts among partners in the textile supply chain. 


\section{RESEARCH FOR CONFLICT MANAGEMENT IN THE TEXTILE SUPPLY CHAIN FROM EXPORTERS' PERSPECTIVES}

If the managers fail to manage the entire textile supply chain without any conflicts between the partners, the supply chain cannot work efficiently. As a matter of fact, conflict is inevitable in every organizations, companies and supply chain. However, it is important to search what are the sources of conflict, how the managers of textile companies handle with, and resolve these conflicts. However, little attention has been given to identifying differences between upstream and downstream supplychain based conflict. In addition to identify the sources and resolutions of textile supply chain-based conflict, the findings of this survey contribute to determine the differences between upstream and downstream textile supply chain-based conflicts. A questionnaire survey was developed and pilot tested. The alternative hypotheses of the survey are as following:

$H_{1}$ : The sources of conflict are different between upstream and downstream supply chain.

$\mathrm{H}_{2}$ : The methods of conflict resolution are different between upstream and downstream supply chain.

\section{Research Methodology}

Data for this research was collected through survey methodology from the managers of the textile exporters in Denizli, Turkey. The questionnaire was developed and adapted from the existing studies (Thomas, 1976; Bradford et al., 2004; Arend et al., 2005; Lam et al., 2007) and self-created. Before being conducted, the questionnaire was pre-tested on three managers in order to construct validity of measurement scales.

Sample size is determined as 125 questionnaires because of the time and cost limitations. Judgmental sampling, one of the non-probability sampling methods, is used to select 25 textile exporters and 125 respondents in Denizli, Turkey. 125 questionnaires were distributed to textile companies. 95 questionnaires returned and 87 of them were usable for the final data analysis. In the questionnaire, there were 14 questions. In the first section, there were 4 questions provided respondents' positions, profiles of the company (sizes, types and their supplied products and services). In the second section, there were 2 questions provided attitudes towards supply chain-based conflicts (5-point scale, 1-strongly disagree, 5-strongly agree) and whether the conflict occurs or not. In the third section, there were 8 questions and 58 items about supplier/customer selections, the sources of conflicts and the resolutions of conflict for downstream and upstream partners separately. In this section, the respondents were asked to rank the factors supplier/customer selection from the most-preferred to the least-preferred with an ordinal measurement scale, also asked to indicate on a 5-point scale how often conflict had occurred in their supply chain activities (1-never, 5-always) and which strategies had been used to solve supply chain-based conflict (1- never, 5-always) in upstream and downstream suppliers separately. SPSS 16.0 for Windows were used to analyze survey data. Descriptive data analysis was used to analyze data collected from survey. The hypotheses are empirically tested by independent samples t-tests. The reliability of the questionnaires was assessed by the Cronbach alpha reliability coefficient. Reliability value calculated 0,826 and exceeded the suggested value of 0,70 . This survey is delimited in two ways. Firstly, instead of personality-based, conflicts are studied on the supply chain-based. Secondly, the pilot survey is conducted in Denizli, Turkey due to limited time.

\section{Research Results}

Table 1 provides the characteristics of respondents and companies of the sample. In terms of the respondents' positions, among the 87 respondents, 21,8\% were general managers, $18,4 \%$ were purchase managers, $19,5 \%$ were operation managers, and $8 \%$ marked the others were finance and accounting managers. In terms of the company sizes, there are 37 companies employing less than 200 workers, 18 companies employing between 201 and 400 workers, 16 companies employing between 801 and 1200 workers. In terms of the supplied products and services from downstream partners, among 87 compa-nies, 94,3\% (82 companies) are providing logistics and transportation services, 90,8\% (79 companies) are providing Cotton \& Thread, 75,9\% (66 companies) are providing Painting \& Printing and 11,5\%(5 companies) are providing Packaging and Security services from their textile supply chain partners. 
Moreover, among the 87 companies, 28,7\% has between 5001 and 10000 square meters, and 25,3\% has between 1001 and 5000 square meters production areas.

\begin{tabular}{|l|c|c|l|c|c|}
\hline \multicolumn{5}{|c|}{ Table 1: The characteristics of respondents and companies } \\
\hline \multicolumn{1}{|c|}{ Variable } & N & $\%$ & \multicolumn{1}{|c|}{ Variable } & N \\
\hline Respondent's positions & & & \multicolumn{1}{|c|}{ Supplied products and services } & & \\
\hline Owners & 15 & 17,2 & Cotton \& Thread & 79 & 90,8 \\
\hline General Managers & 19 & 21,8 & Weaving \& Knitting & 75 & 86,2 \\
\hline Operation Managers & 17 & 19,5 & Painting \& Printing & 66 & 75,9 \\
\hline Purchasing Managers & 16 & 18,4 & Sewing & 44 & 50,6 \\
\hline Marketing\& Export Managers & 13 & 14,9 & Logistics & 52 & 94,3 \\
\hline Others & 7 & 8,0 & Others & & 11,5 \\
\hline The number of workers & & & & 4 & 4,6 \\
\hline$\leq 200$ & 37 & 42,5 & $\leq 1000$ square meters & 22 & 25,3 \\
\hline $201-400$ & 18 & 20,7 & $1001-5000$ square meters & 25 & 28,7 \\
\hline $401-800$ & 12 & 13,8 & $5001-10000$ square meters & 21 & 24,1 \\
\hline $801-1200$ & 16 & 18,4 & $10001-15000$ square meters & 15 & 17,2 \\
\hline$\geq 1201$ & 4 & 4,6 & $\geq 15001$ square meters & & 5 \\
\hline
\end{tabular}

According to survey results, 72 of the 87 companies are in a conflict with their supply chain partners, and 15 of them are not. Given the survey results, it appears that there are many conflicts on the textile supply chain. As seen in Table 2, this result is also supported by respondents' attitudes towards supply chain-based conflicts. The respondents of the survey believe that the textile supply chain-based conflict is inevitable between supply chain partners. Besides, they manage the textile supply chain-based conflict successfully in their management control areas. They also agree that the conflict can degrade their performance. However, they consider that their partners do not manage the textile supply chainbased conflict successfully as much as they manage.

\section{Table 2: Attitudes towards supply chain-based conflict}

\begin{tabular}{|l|c|c|}
\hline Attitude statements* & Mean & Std. Deviation \\
\hline The conflicts are inevitable between companies in the textile supply chains. & 3,9625 &, 86337 \\
\hline The conflicts in our management control areas are managed very well. & 4,0875 &, 67868 \\
\hline The conflicts can degrade the performance of the textile supply chain. & 3,6000 & 1,19704 \\
\hline The managers with whom we are disagreement handle conflict very well. & 3,1000 & 1,01383 \\
\hline
\end{tabular}

*Scale: 1. Strongly Disagree - 5 Strongly Agree

It is crucial to understand the sources of the conflicts before using strategies to solve them. The sources of supply chain-based conflicts with downstream and upstream partners are presented in Table 3. As the statistics make clear, the fact that supply chain-based conflict exists, and the levels of the supply chain-based conflict differ considerably in terms of their sources. The main sources of conflict with downstream partners are price changes, last minute changes in orders, substandard performance for delivery and quality, demand for faster delivery, delayed payment, volume changes in orders, by whom logistics/transportation cost will be paid, and order cancellations. The main sources of conflict with upstream partners are demand for faster delivery, last minute changes in orders, price changes, substandard performance for delivery and quality, volume changes in orders and lack of cooperation. Thus, conflict is common between the supply chain partners, and there are different types of conflicts in the textile supply chain. The underlying sources of most conflicts are price changes for downstream partners, the demand for faster delivery from upstream partners and last minute changes in their orders for both of them. 
Although conflict is common between textile supply chain partners and there are some kinds of conflicts arisen in the supply chain, it is also important to compare the sources of conflicts between downstream and upstream partners. In testing $\mathrm{H}_{1 \mathrm{i}}$, to compare the sources of conflicts, independent-samples $\mathrm{T}$-tests were performed to determine the differences between them. The results of testing on the main differences of them are presented in Table 3. According to statistical analysis, some sources of conflict appear to display notable differences. For example, a price change, substandard product and service quality performance, delayed payment, non-compliance company rules and policies and the logistics/transportation costs in the downstream supply chain are more important reasons to come into conflict than upstream supply chain. In contrast, demand for faster delivery in the upstream supply chain is more important reason to conflict than downstream supply chain. As a result, the alternative hypotheses such as $\mathrm{H}_{1 \mathrm{a}}, \mathrm{H}_{1 \mathrm{~d}}, \mathrm{H}_{1 \mathrm{f}}, \mathrm{H}_{1 \mathrm{~g}}, \mathrm{H}_{11}$ and $\mathrm{H}_{1 \mathrm{n}}$ are accepted. Findings indicate that in comparison to downstream partners, the level of conflicts with upstream partner is lower. Consequently, the sources of textile supply chain-based conflicts are different between downstream and upstream partners.

Table 3: The sources of conflict in downstream and upstream partners

\begin{tabular}{|c|c|c|c|c|c|c|}
\hline \multirow[t]{2}{*}{ The sources of conflict* } & \multicolumn{2}{|c|}{ Downstream Partners } & \multicolumn{2}{|c|}{ Upstream Partners } & \multirow{2}{*}{$\mathrm{t}^{* *}$} & \multirow{2}{*}{$\mathrm{p}$} \\
\hline & Mean & Std. Deviation & Mean & Std. Deviation & & \\
\hline Changes in price & 3,2375 & ,83049 & 2,6625 & 87067 & 4,274 &, $000 * * *$ \\
\hline Changes at the last minute & 2,8750 & 1,11803 & 2,9872 &, 81374 &,- 720 & ,473 \\
\hline Changes in volume & 2,3500 & ,90148 & 2,4375 & 1,06550 &,- 561 &, 576 \\
\hline Faster delivery & 2,6625 & 1,09016 & 3,1375 & 1,11086 & $-2,730$ &, $007 * * *$ \\
\hline Order cancellations & 2,1000 & ,94935 & 1,8875 & ,77938 & 1,547 &, 124 \\
\hline Substandard performance & 2,8125 & 1,17024 & 2,2875 & 1,05775 & 2,977 &, $003 * * *$ \\
\hline Delayed payment & 2,4250 & 1,06468 & 1,9250 & 1,07650 & 2,954 &, $004 * * *$ \\
\hline Poor communication channels & 1,9250 & ,68943 & 1,9625 &, 81821 &,- 313 & ,754 \\
\hline Value and goal differences & 1,9125 &, 55561 & 1,9500 & ,96653 &,- 301 &, 764 \\
\hline Personality clashes & 1,8125 &, 81277 & 1,9375 & 84709 &,- 952 &, 342 \\
\hline Lack of cooperation & 2,0375 &, 84858 & 2,0250 & 1,21150 & ,076 & ,940 \\
\hline Noncompliance policies & 1,9375 &, 81666 & 1,5625 & ,79307 & 2,946 &, $004 * * *$ \\
\hline Friction between managers/owners & 1,6250 & ,60326 & 1,4250 & ,68943 & 1,953 &, 053 \\
\hline The cost of logistics/transportation & 2,1125 & 1,10228 & 1,7500 & 1,01258 & 2,166 &, $032 * * *$ \\
\hline
\end{tabular}

* Scale: 1. Never - 5. Always

** Equal variances assumed

$* * * \mathrm{p} \leq 0,05$

Managing supply chain-conflict is one of the major responsibilities of the textile managers, and is an important skill to use when working as supply chain partners. Thus, the textile supply chain-based conflict ought to be managed either resolved or used beneficially. As seen in Table 4, respondents have tried to solve the supply chain-conflicts rather than ignore and avoid them. The main resolution methods, a range of methods for alleviating or eliminating sources of conflict, with downstream partners preferred by textile managers are compromising, sharing, smoothing, offering options, joint planning and competing, but methods such as handling authority and power, bargaining, collaborating, avoiding and forming strategic supplier alliance are the least methods preferred. However, the main resolution methods with upstream partners preferred by textile managers are sharing, compromising, offering options, developing trust, collaborating joint planning and smoothing. The respondents do not prefer to use conflict resolution methods with upstream partners such as avoiding, handling authority and power, forming supplier alliances and competing. Besides, sharing, each party making some concessions in order to reach the midway solutions, has been preferred for all supply chain partners. It is also important that avoiding conflict is one of the least preferred methods since it has some negative consequences. 
It is also important to compare the resolution methods between downstream and upstream partners. The results of testing the main differences of them are presented in Table 4. According to statistical analysis, the preferred conflict resolutions methods are different between downstream and upstream partners. For example, the some conflict handling methods for upstream partners such as competing, avoiding and handling authority and power are less preferred than downstream partners. In addition to this, developing trust and forming strategic supplier alliances are more preferred for upstream partners than downstream partners. As a result, the alternative hypotheses such as $\mathrm{H}_{2 \mathrm{a}}, \mathrm{H}_{1 \mathrm{~d}}, \mathrm{H}_{2 \mathrm{e}}, \mathrm{H}_{2 \mathrm{f}}, \mathrm{H}_{2 \mathrm{j}}$ and $\mathrm{H}_{2 \mathrm{~m}}$ are accepted. Based on a comparison of conflict resolution methods, it appears that the preferred conflict resolution methods in the textile supply chain-based conflicts are different between downstream and upstream partners. For example, competing with partners, a win-or-lose style of handling conflicts has been preferred from downstream partners rather than upstream partners. Offering options, third options for bringing the conflicting parties together, has been preferred more by upstream rather than downstream partners. The surveyed textile companies have used conflict resolutions methods such as avoiding and handling authority and power for downstream partners rather than upstream partners. Moreover, collaborating is one of the ideal ways of resolution to conflict, and respondents have been more willing to collaborate and work together for finding some solutions with upstream partners rather than downstream partners.

\section{Table 4: Conflict handling methods for downstream and upstream partners}

\begin{tabular}{|c|c|c|c|c|c|c|}
\hline \multirow[t]{2}{*}{ Conflict handling methods* } & \multicolumn{2}{|c|}{ Downstream Partners } & \multicolumn{2}{|c|}{ Upstream Partners } & \multirow{2}{*}{$\mathrm{t}^{* *}$} & \multirow{2}{*}{$\mathrm{p}$} \\
\hline & Mean & Std. Deviation & Mean & Std. Deviation & & \\
\hline Competing & 2,9750 & 1,00599 & 2,1625 & 1,08434 & 4,913 &, $000 * * *$ \\
\hline Sharing & 3,4000 & ,94935 & 3,4500 & 1,21071 &,- 291 & ,772 \\
\hline Compromising & 3,5250 & 1,05513 & 3,4000 & 1,27884 & ,674 &, 501 \\
\hline Avoiding & 1,7375 &, 88223 & 1,4250 &, 56870 & 2,663 &, $009 * * *$ \\
\hline Handling authority and power & 2,5000 & 1,01881 & 1,7125 & ,79863 & 5,441 &, $000 * * *$ \\
\hline Collaborating & 2,9500 & 1,33027 & 3,3625 & 1,10515 & $-2,133$ &, $034 * * *$ \\
\hline Bargaining & 3,1625 & 1,11881 & 3,4250 & 1,32908 & $-1,351$ & , 178 \\
\hline Offering options & 2,2875 & ,94392 & 2,3125 & 1,23856 &,- 144 & ,886 \\
\hline Smoothing & 3,3875 & 1,24772 & 3,2375 & 1,38018 &, 721 & ,472 \\
\hline Developing trust & 2,9125 & 1,37052 & 3,3875 & 1,38247 & $-2,182$ &, $031 * * *$ \\
\hline Joint planning & 3,0125 & 1,47977 & 3,3625 & 1,51986 & $-1,476$ & , 142 \\
\hline Forming joint problem solving unit & 2,0375 & 1,18475 & 2,3375 & 1,46645 & $-1,423$ & ,157 \\
\hline Forming supplier alliances & 1,7375 & 1,05235 & 2,1125 & 1,20120 & $-2,100$ &, $037 * * *$ \\
\hline
\end{tabular}

* Scale: 1. Never - 5. Always

** Equal variances assumed

$* * * \mathrm{p} \leq 0,05$

The respondents ranked 7 factors when they were choosing key downstream partners in terms of priority from the most-important to the least-important with an ordinal measurement scale. According to 54 responders' valid answers within 87, they have chosen upstream suppliers by the order their priorities; (1) offered price of their materials, parts and services, (2) quality of their products and services, (3) ability to meet delivery due dates, (4) past and current relationship, (5) ISO 9000 certification, (6) offered flexible contract and terms and (7) willingness to integrate relationship. Moreover, 56 respondents also ranked 6 factors when they were choosing key upstream partners. In accordance with 56 responders' valid answers, they have chosen upstream suppliers by the order their priorities; (1) offered price, (2) company sizes, (3) their abilities to respond to their demands, (4) trust, (5) willingness to relationship and (6) past and current relationship. In terms of their priorities for choosing key downstream partners and upstream partners, the differences between the managers who face with the conflicts and the managers who do not face with the conflicts in their textile supply chains are also analyzed. The respondents who face supply chain-based conflicts choose their upstream and downstream suppliers price, cost, quality and relationship oriented. In contrast, the respondents who do not face supply chain-based conflicts choose their upstream and downstream suppliers quality, relationship, 
trust and price oriented. Therefore, there are some differences the selection methods of supply chain partners between the respondents who face conflict and the respondents who do not face conflict in their textile-based supply chain.

\section{CONCLUSION}

Supply chain management, conflict management and supply chain-based conflict management have become some of the popular topics. The growing importance of buyer-supplier relationship urges a need to study conflict and conflict management in the supply chain processes. To implement supply chain management processes successfully, managers who are responsible from supply chain should manage conflict occurred among companies, their suppliers, distributors, retailers and customers etc. Managers who do not manage conflict in supply chain effectively may possibly fail to manage their companies and lose not only money but also their suppliers or customers. Nowadays, the entire supply chain is becoming increasingly important in many industries, and this is especially right for the textile industry. One of the major components of valuable textile supply chain management is effective communication, the ability to work effectively and the ability to handle conflicts between supply chain partners. In sum up, in order to high performance of supply chain, companies must operate supply chain functions in a coordinated manner. The ability to determine the sources of conflicts would be an important benefit because the conflict can degrade the performance of the textile supply chain.

According to survey results, the respondents consider that the textile supply chain-based conflict is unavoidable and common between the supply chain partners. They also believe that their partners do not manage the textile supply chain-based conflict successfully as much as they manage. There are different types of conflicts in the textile supply chain. The underlying sources of the most of the conflicts are price changes for downstream partners, the demand of faster delivery for upstream partners. Moreover, the sources of textile supply chain-based conflicts are different between downstream and upstream partners. Textile managers have applied various methods for supply chain-based conflict resolution such as compromising, sharing, smoothing, offering options, joint planning and competing in downstream supply chain. The methods such as sharing, compromising, offering options, developing trust are preferred to solve the conflicts with upstream suppliers. Avoiding of conflict is one of the least preferred methods both downstream and upstream partners. In terms of textile managers' conflict handling methods, there are some differences between upstream and downstream supply chains. Given the results of this survey, most of the respondents have their own conflict handling methods.

From the perspective of the textile exporter, some managerial implications seem very clear. Specifically, the literature and survey results help textile managers to be aware of the existence of supply chain based-conflict in their textile supply chain. They also enable practitioners and academicians to identify conflict management for both downstream and upstream suppliers separately, and conceptualize supply chain-based conflicts as their relative importance. Moreover, there are also several ideas for future researches. In further studies, the relationship between the personalities (Pragmatist, Idealist, Hothead, Tyrant etc.) of managers and their effects on preferring conflict handling methods should be investigated. 


\section{REFERENCES}

Arend, R.J., Winser, J.D. (2005) Small Business and Supply Chain Management: İs There a Fit?, Journal of Business Venturing, Vol. 20, 403-36.

Ballou, R.H., Gilbert, S.M., Mukherjee, A. (2000) New Managerial Challenges From Supply Chain Opportunities, Industrial Marketing Management, Vol. 29 (1), 7-18.

Barutçu, S. Aydemir M. Barutçu, E. (2005) Conflict Management in Supply Chain, $3^{\text {rd }}$ International Logistics and Supply Chain Congress Proceedings, 466-475.

Barutcu, S., Tanyeri, M. (2004) Strategic Supplier Alliances (Strategic Alliances in Supply Chain Management), International Logistics Congress 2004 Proceedings, Vol. I, 289-297.

Blackhursta, J., Wu, T.T., Craigheadc, C.W. (2008) Asystematic Approach for Supply Chain Conflict Detection with a Hierarchical Petri Net Extension, Omega Vol.36, 680-696.

Bradford, K.D., Stringfellowb, A., Weitzc, B.A. (2004) Managing conflict to improve the effectiveness of retail networks, Journal of Retailing, Vol. 80, 181-195.

Brewer, P.C., Speh, T.W. (2000) Using the Balanced Scorecard to Measure Supply Chain Performance, Journal of Business Logistics, 21(1), 75-9.

Christopher, M. (2000) The Agile Supply Chain: Competing in Volatile Markets, Industrial Marketing Management, Vol. 29(1), 37-44.

Cooper, M., Lambert, D., Pagh, J. (1997) Supply Chain Management: More Than Just a Name for Logistics, The International Journal of Logistics Management, Vol. 8(1), 1-14.

Coughlan, A., Erin, A., Louis, S., El-Ansary, A. (2001) Marketing Channels, Sixth Edition, Prentice Hall, NJ, USA.

Daft, L. Richard. (1997) Management, 4th Edition, The Dryden Press, Florida, USA.

Fiore, T. (2004) Resolving Workplace Conflict: 4 Ways to a Win-Win Solution, http:// www.webpronews. com /topnews/2004/06/02/resolving-workplace-conflict-ways-to-a-winwinsolution, 15.04.2010.

Geyskens, I., Steenkamp, J.B.E.M., Nirmalya, K. (1998) Generalizations about trust in marketing channel relationships using meta analysis, International Journal of Research in Marketing, Vol.15(1), 223-248.

Gibson, J. L., Ivancevich, J. M., Donnelly, J.H. (1997) Organizations, IrwinMcGraw-Hill, USA.

Griffin, R.W. (1990) Management, Houghton Mifflin Company, Boston, CT, USA.

Gunasekaran, A. Lai, K., Cheng, T.C.E. (2008) Responsive Supply Chain: A competitive Strategy in a Networked Economy, Omega, Vol. 36(4), 549-564.

Handfield, R.B., Nichols, E.L. (1999), Introduction to Supply Chain Management, Prentice Hall, NJ, USA

Hau L.L. (1997) Supply Chains, Harvard Business Review, May/Jun, Vol. 75 (3), 190-192.

Hult, G.T.M., Ketchen, D.J., Arrfelt, M. (2007) Strategic Supply Chain Management: improving Performance Through a Culture of Competitiveness and Knowledge Development, Strategic Management Journal, Vol. 28 (10), 1035-1052.

Johnston, A. D., McCutcheon, M. D., Stuart, F. I., Kerwood, H. (2004) Effects of Supplier Trust on Performance of Cooperative Supplier Relationships, Journal of Operations Management, Vol.22 (1), 23-38 
Kozan, M.K., Wasti, S.N., Kuman, A. (2006) Management of Buyer-Supplier Conflict: The Case of the Turkish Automotive Industry, Journal of Business Research, Vol. 59, 662-670.

Kumar, K., Dissel, H.G. (1996) Sustainable Collaboration: Managing Conflict and Cooperation in Interorganizational systems, MIS Quarterly, 279-300.

Lam, P.K, Chin, K.S. (2005) Identifying and Prioritizing Critical Success Factors for Conflict Management in Collaborative New Product Development, Industrial Marketing Management, Vol. 34(8), 761-772.

Lam, P.K., Chin, K.S. Pun, F.T. (2007) Managing Conflict in Collaborative New Product Development: a Supplier Perspective, International Journal of Quality \& Reliability Management, Vol.24 (9), 891-907.

Lambert, D. M., Martha C. C., Janus D. P. (1998) Supply Chain Management: Implementation Issues and Research Opportunities, The International Journal of Logistics Management, Vol. 9(2), 1-19.

Lambert, D., Cooper, M. (2000) Issues in Supply Chain Management, Industrial Marketing Management, Vol.29 (1), 65-83.

Lee, H., Whang, S. (1999) Decentralized Multi-echelon Supply Chains: Incentives and Information, Management Science, Vol.45 (5), 633-640.

Lummus, R.R., Vokurka R.J. (1999), Defining Supply Chain Management: A Historical Perspective and Practical Guidelines, Industrial Management \& Data Systems, Vol. 99 (1), 11-17.

Meier, R.L., Williams, M. R., Singley, R.B. (2004) Supply Chain Management: Strategic Factors from the Buyers' Perspective, Journal of Industrial Technology, Vol.20 (March-2), 1-8.

Milgram, L., Spector, A.,Treger M. (1999) Causes of Conflict, Managing Smart, 297.

Newstrom, J.W., Davis, K. (1997) Organizational Behavior, Tenth Edition, McGrawHill, USA

Pondy, L.R. (1967) Organizational Conflict: Concepts and Models, Administrative Science Quarterly, Vol.12(2), 296-320.

Presutti, W. D. Jr. (2003) Supply Management and e-procurement: Creating Value Added in the Supply Chain, Industrial Marketing Management Vol. 32(3), 219-226.

Rahim, M.A. (2001) Managing Conflict in Organizations, Quorum Books, Westport, CT, USA.

Robbins, S. P. (1998) Organizational Behavior, Simon \& Schuster, NJ, USA.

Soroor, J., Tarokh, M.J. (2006) Developing the Next Generation of the Web and Employing its Potentials for Coordinating the Supply Chain Processes in a Mobile Real-time Manner, International Journal of Information Technology, Vol.12(8),1-40.

Stadtler, H. (2004) Supply Chain Management and Advanced Planning - Basics, Overview and Challenges, European Journal of Operational Research, Vol. 163 (3), 575-888.

Thomas, K.W. (1976) Conflict and Conflict Management, Handbook of Industrial and Organizational Psychology ( Editor: Dunnette M.D.), Rand McNally,889-935, Chicago. MI, USA.

Udin, Z.M., Khan K.M., Zairi, M. (2006) A Collaborative Supply Chain Management Framework, Business Process Management Journal, Vol. 12 (3), 361-376.

Vachon, S., Halley, A., Beaulieu, M. (2009) Aligning Competitive Priorities in the Supply Chain: The Role of Interactions with Suppliers, International Journal of Operations \& Production Management, Vol. 29 (4), 322-340. 